\title{
Early career investigator highlight: February
}

\author{
Raissa Nobrega ${ }^{1}$
}

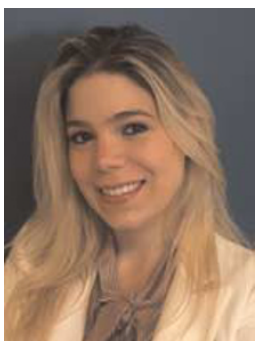

grew up in the Northeast region of Brazil and graduated

from medical school 5 years ago. I initially worked in underserved areas around my hometown as I was looking to give back to my community. My first few jobs were in underserved areas around my hometown as I was looking to give back to my community. Those experiences were eye opening in that I learned to work in settings with very limited resources and to treat gravely ill patients. More than learning about pediatrics, I had a sight of humanity that I am sure very few have had the opportunity to witness. Given my limited resources, I needed to be innovative to overcome many challenges. Those experiences sparked my interest in pediatrics and ultimately led to my choice of pediatric pain as a career path: pain was the most common complaint I had to address. In 2016, I was awarded a Joseph E. Robert Fellowship at the Sheikh Zayed Institute for Pediatric Surgical Innovation at the Children's National Health System in Washington, DC. There I worked with the pain initiative team under the mentorship of two pediatric anesthesiologists,
Drs Quezado and Finkel, and was exposed to experts committed to developing more precise and less invasive procedures, and to developing devices to better the diagnosis of pain and to improving its treatment. Children's National has one of the largest pediatric sickle cell programs in the country and I was able to see a number of patients admitted with severe pain repeatedly. In an effort to decrease opioid intake, ketamine has been explored as an adjuvant to opioids to treat sickle cell patients admitted with vaso-occlusive crisis. Those patients can have a broad spectrum of pain phenotype and many will develop chronic pain. In this study, we sought to determine whether patient characteristics altered the response to ketamine during pain crisis. While this study generated some answers, many more questions need to be answered so that we can help those patients who endure so much pain throughout their lives. I am committed to pursuing the answer to those questions. To that end, after my preliminary year at the Medstar Union Memorial Hospital in Baltimore I am going to join the Anesthesiology Residency program at Massachusetts General Hospital, Boston, after which I will train in pediatric pain medicine. My advice for those initiating their career in medicine is: be curious and passionate about what you choose to do, always learn something, and see the positive side in every experience.

\section{STATEMENT OF FINANCIAL SUPPORT}

No financial support was received for this commentary.

Disclosure: The authors declare no conflict of interest. 